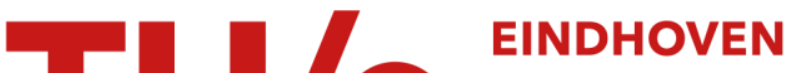

\section{Depletion controlled surface deposition of uncharged colloidal spheres from stable bulk dispersions}

\section{Citation for published version (APA):}

Ouhajji, S., Nylander, T., Piculell, L., Tuinier, R., Linse, P., \& Philipse, A. P. (2016). Depletion controlled surface deposition of uncharged colloidal spheres from stable bulk dispersions. Soft Matter, 12(17), 3963-3971. https://doi.org/10.1039/c5sm02892b

\section{Document license:}

TAVERNE

DOI:

10.1039/c5sm02892b

Document status and date:

Published: 10/03/2016

\section{Document Version:}

Publisher's PDF, also known as Version of Record (includes final page, issue and volume numbers)

\section{Please check the document version of this publication:}

- A submitted manuscript is the version of the article upon submission and before peer-review. There can be important differences between the submitted version and the official published version of record. People interested in the research are advised to contact the author for the final version of the publication, or visit the $\mathrm{DOI}$ to the publisher's website.

- The final author version and the galley proof are versions of the publication after peer review.

- The final published version features the final layout of the paper including the volume, issue and page numbers.

Link to publication

\section{General rights}

Copyright and moral rights for the publications made accessible in the public portal are retained by the authors and/or other copyright owners and it is a condition of accessing publications that users recognise and abide by the legal requirements associated with these rights.

- Users may download and print one copy of any publication from the public portal for the purpose of private study or research.

- You may not further distribute the material or use it for any profit-making activity or commercial gain

- You may freely distribute the URL identifying the publication in the public portal.

If the publication is distributed under the terms of Article 25fa of the Dutch Copyright Act, indicated by the "Taverne" license above, please follow below link for the End User Agreement:

www.tue.nl/taverne

Take down policy

If you believe that this document breaches copyright please contact us at:

openaccess@tue.nl

providing details and we will investigate your claim. 


\section{Soft Matter}

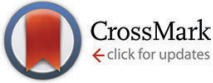

Cite this: Soft Matter, 2016, 12,3963

Received 27th November 2015, Accepted 10th March 2016

DOI: $10.1039 / \mathrm{c} 5 \mathrm{sm} 02892 \mathrm{~b}$

www.rsc.org/softmatter

\section{Depletion controlled surface deposition of uncharged colloidal spheres from stable bulk dispersions}

\author{
Samia Ouhajji, ${ }^{a b}$ Tommy Nylander, $^{b}$ Lennart Piculell, ${ }^{b}$ Remco Tuinier, ${ }^{\text {ac }}$ Per Linse \\ and Albert P. Philipse*a
}

\begin{abstract}
The competition between surface adsorption and bulk aggregation was investigated for silica colloids dispersed in cyclohexane in contact with hydrophobized silica substrates. Central to this study is that the colloids and surfaces have the same material and surface properties. Colloid-colloid and colloid-surface interactions were controlled by addition of polymers providing depletion interaction. Bulk instability was determined by turbidity and viscosity measurements and surface adsorption by ellipsometry measurements. At increasing polymer concentration, strong surface adsorption occurred at polymer concentrations below that required for bulk phase separation. Complementary Monte Carlo simulations with the use of a new weak depletion theory support quantitatively the experimental observation of the existence of an interval of interaction strength at which aggregation in bulk is negligible while surface adsorption is substantial.
\end{abstract}

\section{Introduction}

Surface coatings can be made by particle adsorption from solutions or dispersions onto macroscopic substrates. ${ }^{1,2}$ An example of the latter is the convective assembly used for the fabrication of colloidal crystals. ${ }^{3-5}$ Adsorption from solutions or dispersions has the advantage that adsorption rates can be tuned by varying parameters such as concentration and temperature.

Generally, the intention is to obtain homogeneous surface coatings. However, to achieve an adsorbed layer with closepacked particles is far from trivial. For instance, if particleparticle attractions are too strong, particles may aggregate before adsorbing onto a surface, contributing to inhomogeneous coatings. Particle deposition on surfaces is thus controlled by the delicate balance between particle-particle and particle-surface interactions.

Extensive literature can be found on the competition between bulk aggregation and surface adsorption, ${ }^{6-12}$ appearing when a particle dispersion is in contact with a surface. Wijting et $a l^{13}$ investigated the wetting behaviour in a system of

\footnotetext{
${ }^{a}$ Van't Hoff Laboratory for Physical and Colloid Chemistry,

Debye Institute for Nanomaterials Science, Utrecht University, Padualaan 8 , 3584 CH, The Netherlands.E-mail:S.Ouhajji@uu.nl, A.P.Philipse@uu.nl

${ }^{b}$ Physical Chemistry, Department of Chemistry, Lund University, P.O. Box 124, S-22100 Lund, Sweden

${ }^{c}$ Laboratory of Physical Chemistry, Department of Chemical Engineering and Chemistry and Institute for Complex Molecular Systems, Eindhoven University of Technology, P.O. Box 513, 5600 MB Eindhoven, The Netherlands
}

organophilic silica spheres in cyclohexane with poly(dimethylsiloxane) (PDMS) as depletant. At sufficiently high concentrations of both colloids and polymers, a (colloidal) gas-liquid phase separated system was obtained. Upon approach of the critical point from the two-phase region, the contact angle of the gas-liquid interface on various substrates changed from partial wetting to complete wetting.

Furthermore, fluid-solid transitions on solid substrates were studied with optical microscopy, and a fluid monolayer of large charge-stabilized polystyrene spheres in water at a hard wall was observed at concentrations below the bulk phase boundary. ${ }^{14,15}$ As the concentration of depletant spheres increased, the fluid surface layer became solid, still in coexistence with the bulk fluid. In binary mixtures of colloidal spheres, a surface phase that phase separated before the bulk, purely driven by entropy, was observed. ${ }^{16}$ In a similar system, the occurrence of a wall crystal-fluid coexistence was reported. ${ }^{17}$

In a recent study ${ }^{18}$ using a thermodynamic chemical equilibrium model and Monte Carlo simulations, Linse and Wennerström predict the existence of an interval of interaction strength where surface adsorption is significant while bulk instability through nucleation remains negligible. Two assumptions are central in this study, ${ }^{18}$ viz. (i) the particles and substrates are made of the same material, and (ii) the interaction range is much smaller than the particle size allowing the Derjaguin approximation to be applied. Under these assumptions the particle-surface interaction becomes twice as strong as the particle-particle interaction. At increasing attraction, the thermodynamic model predicted the following scenarios to occur: (A) weak particle adsorption onto the surface, 


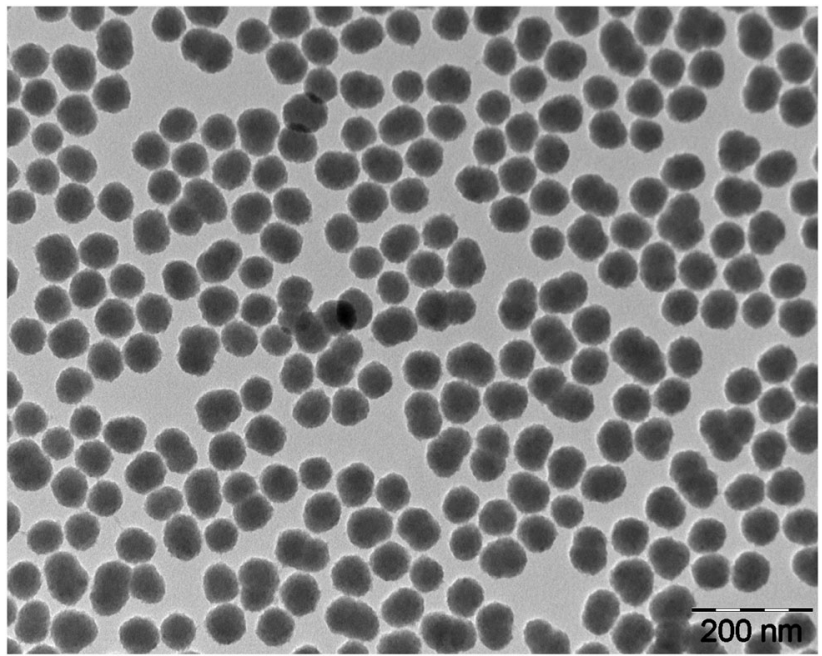

Fig. 1 Typical TEM image of $\mathrm{C}_{18}$-coated silica particles with an average diameter of $64 \pm 5 \mathrm{~nm}$ and apparent hydrodynamic diameter of $74 \pm 14 \mathrm{~nm}$.

(B) particle association on the surface forming a denser single adsorbed layer, (C) formation of a second adsorbed layer on the surface, (D) multiple adsorbed layers on the surface and (E) bulk phase separation.

None of the experimental studies mentioned above, however, has reported results that allow quantitative comparison to the Linse-Wennerström scenario ${ }^{18}$ and its key prediction of significant surface adsorption from a stable hard-sphere fluid. The aim of this paper is to quantitatively test this prediction using the hard-sphere silica colloids developed by Vrij and co-workers. ${ }^{19}$ The effective particle-particle and particlesurface attractions were tuned by adding PDMS as depletant at varying concentrations. The occurrence of bulk aggregation was determined both with turbidity and dynamic light scattering measurements, and surface adsorption from particle dispersion was quantified by ellipsometry. Simulations in combination with recently developed weak-depletion theory ${ }^{20}$ were performed to further underpin and explain our experimental results.

\section{Experimental}

\subsection{Materials}

2.1.1 Chemicals. Cyclohexane (99\%, Sigma-Aldrich) and ethanol (99.7\%, Solveco) were used as solvent. Silica substrates were rinsed with hydrogen peroxide $\left(30 \%\right.$ by weight $\mathrm{H}_{2} \mathrm{O}$, Honeywell Burdick and Jackson), ammonia solution ( $\approx 25 \%$ $\mathrm{NH}_{3}$, Honeywell Burdick and Jackson) and hydrochloric acid (fuming, 37\%, Merck). The substrates were hydrophobized using 1-octadecanol (99\%, Honeywell Burdick and Jackson) dissolved in chloroform (for HPLC, $\geq 99.9 \%$, Sigma-Aldrich). Poly(dimethylsiloxane) (PDMS, Fluka) with a weight average molar mass of $95000 \mathrm{~g} \mathrm{~mol}^{-1}$ and a polydispersity index of 1.9 was used as depletion polymer. The cuvette for ellipsometry was cleaned with $5 \mathrm{v} / \mathrm{v} \%$ Decon 90 (Decon laboratories) in water.
The cuvette for dynamic light scattering was cleaned with Hellmanex (Hellma). All chemicals were used as received and stored at ambient conditions except for hydrogen peroxide which was stored in a refrigerator. All water used in the experiments was purified by a Milli-Q system.

2.1.2 Colloidal system. Silica spheres stabilized with 1-octadecanol in cyclohexane were prepared as described earlier. ${ }^{19,21}$ The silica dispersion had been prepared two decades ago $^{22}$ and clearly has demonstrated a long-term colloidal stability. The van der Waals attraction between two octadecyl-coated silica spheres is minimized because the refractive indices of silica and cyclohexane are closely matched, ${ }^{23}$ and hence the interaction between two colloidal spheres is well represented by a hard-sphere potential. In addition, cyclohexane is a good solvent for the octadecyl coating of the spheres. Transmission electron microscopy (TEM) images (Fig. 1) were used to determine the shape of the particles (Philips TECNAI 12). Due to their small size, the dispersed silica particles are not completely spherical (see Fig. 1). The apparent hydrodynamic diameter of these spheres was $74 \pm$ $14 \mathrm{~nm}$, as determined by dynamic light scattering. PDMS ${ }^{24,25}$ with a radius of gyration $R_{\mathrm{g}}=14.4 \mathrm{~nm}$ was used as depletant. The radius of gyration of PDMS was calculated following Vincent $^{26,27}$ (see Appendix A). The $\theta$-temperature of PDMS in cyclohexane is $-80{ }^{\circ} \mathrm{C}$, so the polymer is in a good solvent at room temperature. ${ }^{28}$ No indications were found that PDMS significantly adsorbs onto the silica particles, see Fig. 6. However, as discussed in Section 4, PDMS is not fully repelled by the silica surfaces.

The phase diagram of the studied system was obtained by mixing varying concentrations of the silica spheres and PDMS. Phase separation, determined by visual inspection of the samples, occurred at sufficiently high concentrations of both colloidal particles and polymer and was typically observed within 30 minutes after mixing the two species. The polymerto-colloid size ratio $R_{\mathrm{g}} / R$, with $R$ the hydrodynamic radius of the colloids, is 0.38 , which in theory allows for colloidal gas, liquid and crystalline phases. ${ }^{29}$ However, only gas-liquid phase separation was observed in the present study.

2.1.3 Substrates. Hydrophobized silica substrates were prepared from 4 inch polished silicon wafers (p-type, boron doped, resistivity of $1-10 \Omega \mathrm{cm}$ ) with a thermally oxidized silica layer of around $300 \AA$, purchased from Semiconductor Wafer Inc., Taiwan. The oxidized silicon wafer was cut into small slides with a width of about $1 \mathrm{~cm}$ and a length of $2-3 \mathrm{~cm}$. Prior to use, the substrates were cleaned in an alkaline mixture of $\mathrm{NH}_{4} \mathrm{OH}$, $\mathrm{H}_{2} \mathrm{O}_{2}$ and $\mathrm{H}_{2} \mathrm{O}\left(3: 3: 16\right.$ by volume) at $80{ }^{\circ} \mathrm{C}$ for 5 minutes and rinsed with water, followed by an acid mixture consisting of $\mathrm{HCl}, \mathrm{H}_{2} \mathrm{O}_{2}$ and $\mathrm{H}_{2} \mathrm{O}(3: 3: 16$ by volume $)$ at $80{ }^{\circ} \mathrm{C}$ for 10 minutes, after which they were thoroughly rinsed with water and then with ethanol. Finally, the substrates were stored in ethanol.

The substrates were hydrophobized in a melt of 1-octadecanol. Prior to hydrophobization, the silica substrates were rinsed with ethanol, dried with nitrogen and plasma cleaned in low pressure air at a pressure of 0.0001 mbar for 5 minutes (Harrick Scientific Corp Plasma Cleaner, Model PDC-3XG) to remove any 
organic impurities. In a two-neck round-bottom flask, 30 grams of 1-octadecanol was heated to $180-200{ }^{\circ} \mathrm{C}$ while stirring with a mechanical stirrer. A silica substrate was placed in this melt for 3-4 hours. The hydrophobized substrate was rinsed three times in pre-heated chloroform at about $55{ }^{\circ} \mathrm{C}$, sonicated in ethanol for 15 minutes and, finally, stored in ethanol. Before ellipsometry experiments, substrates were rinsed with ethanol and dried with nitrogen.

\subsection{Methods}

2.2.1 Ellipsometry. Surface adsorption was monitored in situ by null ellipsometry measurements. A modified, automated Rudolph research thin-film null ellipsometer (model 43603-200E) was used, as described in detail by Tiberg and Landgren. ${ }^{30}$ The instrument was equipped with high-precision step motors and controlled by a personal computer. A xenon arc lamp, filtered to a wavelength of $401.5 \mathrm{~nm}$, was used as the light source. Measurements were performed at an angle of incidence of $67.87^{\circ}$. The substrate was mounted vertically in a $7 \mathrm{~mL}$ trapezoid cuvette made of optical glass and thermostated to $25{ }^{\circ} \mathrm{C}$. A magnetic stirrer agitated the sample at about $300 \mathrm{rpm}$. An inlet and an outlet tube in the cuvette were connected to a HPLC pump and a multichannel peristaltic pump, respectively, in order to change the solution without emptying the cuvette. Due to the volatile nature of the solvent, additional cyclohexane was added every minute by the HPLC pump to maintain a constant sample volume.

Prior to each experiment, the refractive index and the thickness of the silica substrate were determined using a three-layer model of bulk silicon with a silica layer in a surrounding medium. To this end, the ellipsometric angles $\Psi$ and $\Delta$ were measured in two different media and corrections were made for optical imperfections of the instrument by averaging over four zones. Typical values of the refractive indices were $5.5-0.3 j$ for bulk silicon and 1.48 for the thermally grown silicon oxide film with a thickness of $300 \pm 20 \AA$.

After characterization of the optical properties of the substrate with the oxide layer, the thickness and refractive index of an additional adsorbed layer are obtained using a four-layer model from recorded changes in $\Psi$ and $\Delta$ as a function of time. From these values, the adsorbed amount $\Gamma$ can be calculated as a function of the bulk concentration, using de Feijter's approximation, ${ }^{31}$ according to:

$$
\Gamma=d_{\mathrm{f}} \frac{n_{\mathrm{f}}-n_{0}}{\mathrm{~d} n / \mathrm{d} c}
$$

with $d_{\mathrm{f}}$ being the thickness and $n_{\mathrm{f}}$ the refractive index of the adsorbed film, $n_{0}$ the refractive index of the solvent and $\mathrm{d} n / \mathrm{d} c$ the refractive index increment of the adsorbed substance. The refractive index increment of the silica dispersion was measured using a multi-wavelength refractometer (Abbe 60/ED from Bellingham and Stanley Ltd) and had a value of $0.00973 \mathrm{~mL} \mathrm{~g}^{-1}$.

Concentrated silica dispersion was added to about $5 \mathrm{~mL}$ cyclohexane in the cuvette to a final silica concentration of 3 volume percent followed by addition of PDMS with varying concentrations $\left(0-14 \mathrm{mg} \mathrm{mL}^{-1}\right)$.
2.2.2 Dynamic light scattering. The apparent hydrodynamic diameter of the silica spheres in absence and presence of depletant was measured by dynamic light scattering using a Malvern Instruments Zetasizer Nano-ZS. A quartz cuvette was filled with $2 \mathrm{~mL}$ samples containing $3 \mathrm{v} / \mathrm{v} \%$ silica particles and 0-14 $\mathrm{mg} \mathrm{mL}^{-1}$ PDMS in cyclohexane. Prior to the measurements, the samples were filtered through a syringe filter (PTFE membrane, $0.20 \mu \mathrm{m}$, Minisart). Measurements were performed at $25{ }^{\circ} \mathrm{C}$ after ten minutes of equilibration at an angle of incidence of $173^{\circ}$. The obtained apparent hydrodynamic diameter was averaged over ten measurements.

2.2.3 Turbidity. Turbidities were determined by measuring the transmittance $T$ of $2 \mathrm{~mL}$ samples containing $3 \mathrm{v} / \mathrm{v} \%$ silica spheres and $0-14 \mathrm{mg} \mathrm{mL}^{-1}$ PDMS in cyclohexane using a Varian Cary WinUV spectrophotometer. The transmittance of pure cyclohexane was measured as well. Measurements were performed in a thermostated quartz cuvette at $25{ }^{\circ} \mathrm{C}$ in the wavelength range of 200 to $800 \mathrm{~nm}$ every $0.500 \mathrm{~nm}$ at a scan rate of $300 \mathrm{~nm} \mathrm{~min}{ }^{-1}$ with an average time of $0.1 \mathrm{~s}$ and a spectral bandwidth of $2.0 \mathrm{~nm}$.

The relative turbidity was related to the transmittance according to eqn (2):

$$
\text { Relative turbidity }=\frac{T_{\text {solvent }}-T_{\text {sample }}}{T_{\text {solvent }}}
$$

at wavelength $401.5 \mathrm{~nm}$, the same as for the ellipsometery measurements.

\section{Experimental results and discussion}

\subsection{Colloids and substrates}

The phase diagram of the colloid-polymer mixture is shown in Fig. 2. Experiments were performed with samples containing $3 \mathrm{v} / \mathrm{v} \%$ silica spheres and $0-14 \mathrm{mg} \mathrm{mL}^{-1}$ PDMS, which was found to be in the one-phase region of the system.

The silica substrates were hydrophobized by the same method as the silica spheres, namely in a melt of 1-octadecanol.

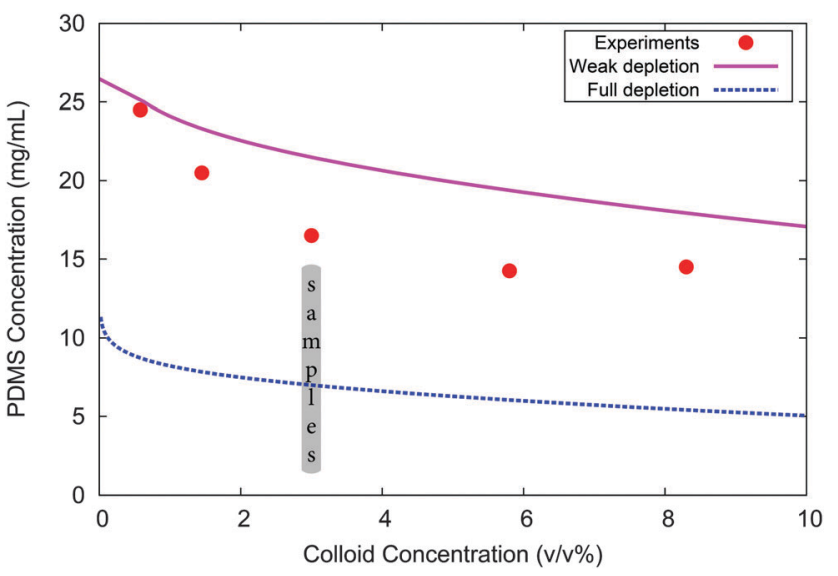

Fig. 2 Experimental and theoretical phase diagrams of mixtures of hydrophobized silica spheres and PDMS. Above the phase boundary liquid-gas phase separation is observed. The compositions of the samples used in our study are indicated by the vertical grey bar. 
Although the same treatment does not guarantee equal surface density of octadecyl chains, it does ensure that the chemical nature of the surfaces is the same. The water contact angle on the silica substrates was $91.5^{\circ}$ and gives an indication of effective hydrophobization. From AFM images (not shown) it was deduced that the surfaces were overall smooth with roughness on the order of a few nanometres. However, occasionally large surface irregularities up to $200 \mathrm{~nm}$ could be found. These objects are likely to be impurities like dust as the hydrophobic surface tends to attract impurities. The substrates were therefore stored in ethanol to reduce the risk of surface contamination.

We also prepared $\mathrm{C}_{18}$ silica substrates in a solution of 1-octadecanol in triethyl phosphate. ${ }^{32}$ However, it was found that the surface layers were unstable, giving poor reproducibility of the adsorption data. Possibly these effects stem from partial dissolution of the stearyl layer, resulting in less hydrophobic and less smooth surfaces.

\subsection{Surface adsorption}

A typical example of the adsorbed amount and normalized thickness versus time from an ellipsometry experiment is shown in Fig. 3. In Fig. 4 and 5, the adsorbed amount and the normalized thickness, respectively, are plotted as functions of polymer concentration to illustrate the influence of the depletant and thus the increase in attraction between the particles. The thickness and the adsorbed amount are given at three different times: 53 minutes and 88 minutes after the addition of PDMS and 30 minutes after rinsing (bulk solution replaced by pure solvent). These values represent steady-state conditions.

Fig. 4 shows that adsorption of particles onto a surface arises already in the absence of depletant. This finite adsorption is very likely a consequence of the van der Waals attraction between particles and the surface (see Appendix B). Upon addition of PDMS up to and including a concentration of $6 \mathrm{mg} \mathrm{mL} \mathrm{m}^{-1}$, the adsorbed amount shows a relatively weak increase. Above a depletant concentration of $6 \mathrm{mg} \mathrm{mL} \mathrm{mL}^{-1}$,

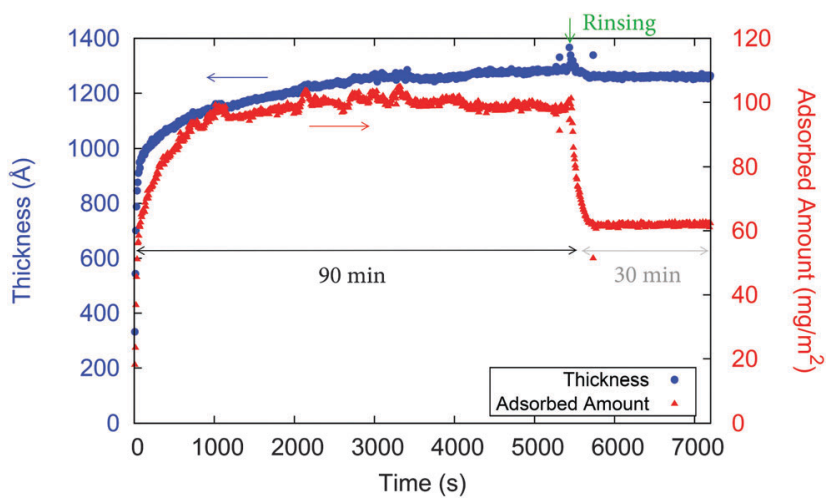

Fig. 3 Adsorbed amount and normalized thickness versus time for the adsorption of silica particles on a hydrophobized silica surface from a $3 \mathrm{v} / \mathrm{v} \%$ silica dispersion with $10 \mathrm{mg} \mathrm{mL}^{-1}$ PDMS in cyclohexane as measured by ellipsometry. The silica dispersion was added at zero time and rinsing was performed after 90 minutes (indicated by the green arrow).

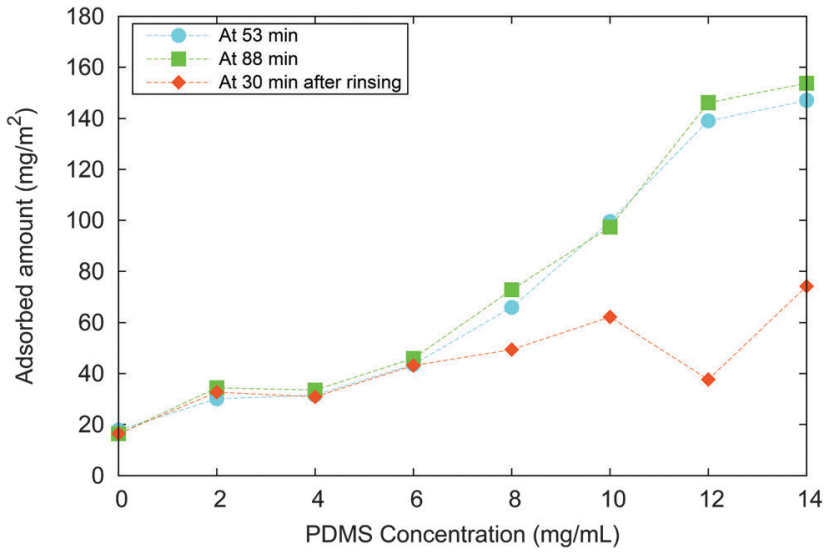

Fig. 4 Adsorbed amount versus PDMS concentration for the adsorption of silica particles on a hydrophobized silica surface from a $3 \mathrm{v} / \mathrm{v} \%$ silica dispersion with added PDMS in cyclohexane after 53 minutes and 88 minutes of adsorption and after 30 minutes of rinsing.

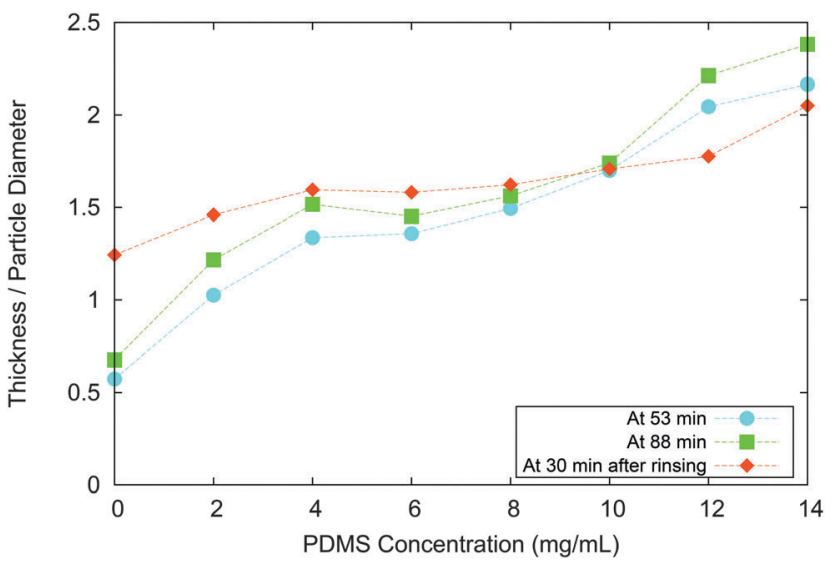

Fig. 5 Thickness of adsorbed layers versus PDMS concentration for the adsorption of silica particles on a hydrophobized silica surface from a $3 \mathrm{v} / \mathrm{v} \%$ silica dispersion with added PDMS in cyclohexane after 53 minutes and 88 minutes of adsorption and after 30 minutes of rinsing.

a steeper increase occurs that levels off again at $12 \mathrm{mg} \mathrm{mL}$. No decrease in adsorbed amount is observed after rinsing, provided that the surface layers are produced at PDMS concentrations of $6 \mathrm{mg} \mathrm{mL^{-1 }}$ or less. However, a significant fraction is removed by rinsing with pure solvent from layers produced at higher PDMS concentrations.

Fig. 5 shows that the normalized thickness follows a similar trend as the adsorbed amount, however, the relative variation with PDMS concentration is much smaller than for the thickness. The thickness increases rapidly up to and including $4 \mathrm{mg} \mathrm{mL}^{-1}$, after which it attains basically a constant value between 4 and $8 \mathrm{mg} \mathrm{mL}^{-1}$ and finally increases again above $8 \mathrm{mg} \mathrm{mL}{ }^{-1}$ PDMS. The fact that the thickness remains constant while the adsorbed amount increases indicates that a more densely packed layer is being formed.

The values of both the adsorbed amount and the normalized thickness recorded after rinsing, increase slightly with the initial PDMS concentration, but the variations are much less than before rinsing, see Fig. 4 and 5 . 


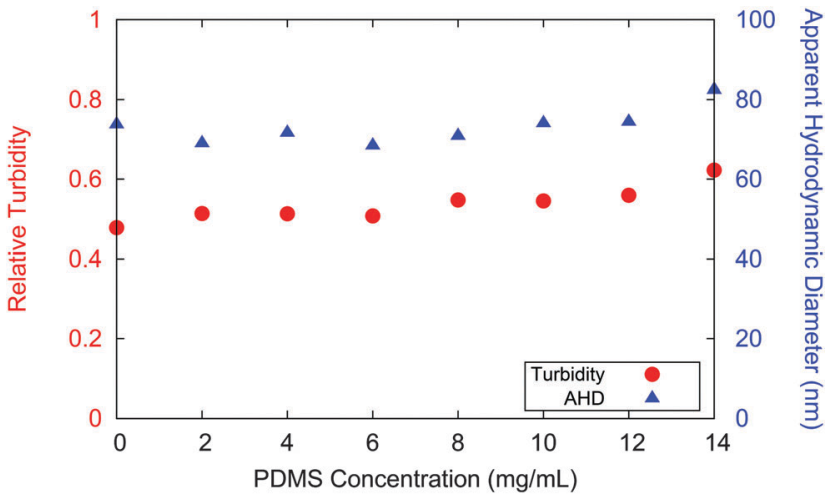

Fig. 6 Turbidity (left $y$-axis) and apparent hydrodynamic diameter (right $y$-axis) versus PDMS concentration of a $3 \mathrm{v} / \mathrm{v} \%$ silica dispersion with added PDMS in cyclohexane. Corrections are made for the increase in sample viscosity due to increasing polymer concentration.

We note in passing that in the theoretical study of depletion driven sphere crystallization on a wall, ${ }^{17}$ the authors 'expect a sharp transition of the whole layer from fluid to crystal with a jump in density'. The much more gradual transition in our experiments possibly stems from the size polydispersity of our silica spheres that suppresses crystallization. In future work this issue could further be studied via computer simulations of depletion driven deposition for monodisperse and slightly polydisperse spheres.

\subsection{Bulk aggregation}

Bulk aggregation was studied for the same samples as used in the surface adsorption experiments. To this end, turbidity and apparent hydrodynamic diameter measurements were performed in the one-phase region of the phase diagram.

3.3.1 Turbidity. The turbidity of a $3 \mathrm{v} / \mathrm{v} \%$ silica particle dispersion versus concentration of PDMS in cyclohexane is shown in Fig. 6. The value of the relative turbidity remains essentially constant over the entire range, fluctuating around 0.5. This clearly shows that the particles do not aggregate in the bulk. Only at the polymer concentration of $14 \mathrm{mg} \mathrm{mL}^{-1}$, close to the bulk phase boundary, a slight increase of the turbidity can be observed.

3.3.2 Apparent hydrodynamic diameter. The apparent hydrodynamic diameter as a function of PDMS concentration is shown in Fig. 6. The data are corrected for the increase of the viscosity of the medium due to the polymer. These results further demonstrate that no bulk aggregation takes place as the hydrodynamic particle diameter hardly changes from about
$70 \mathrm{~nm}$ over the range of polymer concentrations. A slight increase in size can be observed at the highest depletant concentration, see Fig. 6. In addition, these results confirm that PDMS does not significantly adsorb onto the silica spheres.

More importantly, we have experimentally found the existence of an interval of interaction strength, in which bulk aggregation is negligible and surface adsorption substantial. In the next section our experimental findings are directly compared to theory and simulations using our experimental parameters.

\section{Comparison to theory and simulations}

The depletion interaction potential, $W_{\text {dep }}(h)$, between two spheres and a sphere and a planar surface can be calculated using the adsorption method. ${ }^{29}$ The depletion layer is calculated from the negative adsorption of polymer around a colloidal particle $^{33}$ instead of conventionally taking the depletion layer thickness to be equal to the polymer's radius of gyration. This gives the depletion interaction potential:

$$
W_{\mathrm{dep}}(h)=-\int_{0}^{n} \frac{1}{n^{\prime}}\left(\frac{\partial \Pi}{\partial n^{\prime}}\right)[\Gamma(h)-\Gamma(\infty)] \mathrm{d} n^{\prime}
$$

where $n$ denotes the polymer bulk concentration, $\Pi$ the osmotic pressure of the solution and $\Gamma(h)$ the adsorbed amount of polymer segments at particle separation $h$. Moreover, the number density $n$ equals $3 \phi_{\mathrm{p}} /\left(4 \pi R_{\mathrm{g}}{ }^{3}\right)$ with $R_{\mathrm{g}}$ being the radius of gyration and $\phi_{\mathrm{p}}$ the relative polymer concentration, the latter defined as unity at the overlap concentration. The osmotic compressibility can be written as a function of $\phi_{\mathrm{p}}$ as follows: ${ }^{33}$

$$
\left(\frac{\partial \beta \Pi}{\partial n}\right)=1+2.63 \phi_{\mathrm{p}}\left(\frac{1+3.25 \phi_{\mathrm{p}}+4.15 \phi_{\mathrm{p}}^{2}}{1+1.48 \phi_{\mathrm{p}}}\right)^{0.309}
$$

where $\beta=1 / k T$. For two colloidal hard spheres with radius $R$ in a polymer solution, the adsorbed amount is given by: ${ }^{33}$

$$
\begin{aligned}
& \Gamma(h)-\Gamma(\infty) \\
& = \begin{cases}\frac{2}{3} \pi n \Delta_{\mathrm{s}}{ }^{3}\left(1-\frac{h}{2 \Delta_{\mathrm{s}}}\right)^{2}\left(2+\frac{3 R}{\Delta_{\mathrm{s}}}+\frac{h}{2 \Delta_{\mathrm{s}}}\right) & \text { for } h \leq 2 \Delta_{\mathrm{s}} \\
0 & \text { for } h>2 \Delta_{\mathrm{s}}\end{cases}
\end{aligned}
$$

with $\Delta_{\mathrm{s}}$ being the depletion layer thickness around a sphere. For the interaction between a colloidal sphere and a flat wall, the adsorption follows from: ${ }^{33}$

$$
\Gamma(h)-\Gamma(\infty)= \begin{cases}\frac{4}{3} \pi n\left(R+\Delta_{\mathrm{s}}\right)^{3} & \text { for } h<\Delta_{\mathrm{w}}-2 R-\Delta_{\mathrm{s}} \\ \frac{1}{3} \pi n\left(\Delta_{\mathrm{s}}+\Delta_{\mathrm{w}}-h\right)^{2}\left(3 R+2 \Delta_{\mathrm{s}}-\Delta_{\mathrm{w}}+h\right) & \text { for } \Delta_{\mathrm{w}}-2 R-\Delta_{\mathrm{s}} \leq h \leq \Delta_{\mathrm{w}}+\Delta_{\mathrm{s}} \\ 0 & \text { for } h>\Delta_{\mathrm{w}}+\Delta_{\mathrm{s}}\end{cases}
$$




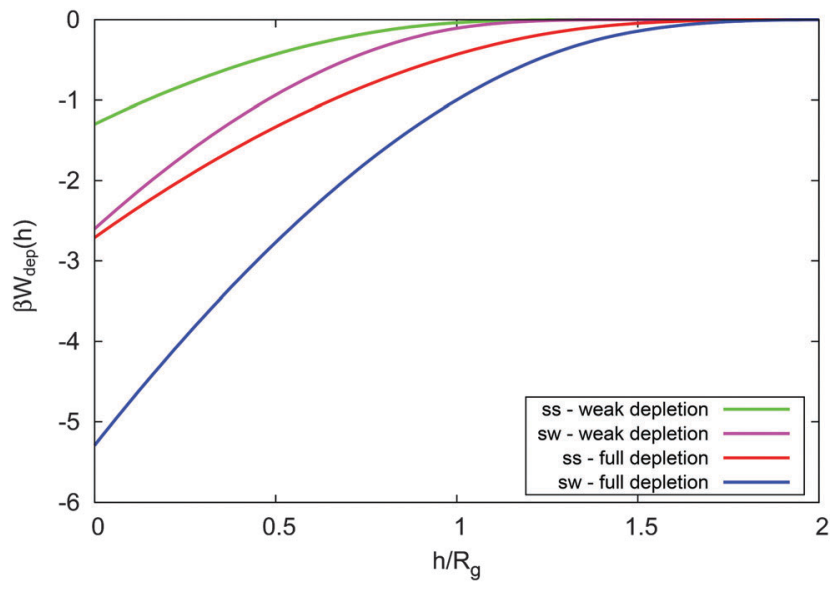

Fig. 7 Full and weak depletion potentials for sphere-sphere (ss) and sphere-wall (sw) interactions at a relative polymer concentration $\phi_{\mathrm{p}}=0.5$

with $\Delta_{\mathrm{w}}$ being the depletion layer thickness near a single flat wall. The quantities $\Delta_{\mathrm{w}}$ and $\Delta_{\mathrm{s}}$ are given by respectively: ${ }^{29}$

$$
\begin{gathered}
\Delta_{\mathrm{w}}=\frac{1.07 R_{\mathrm{g}}}{\sqrt{1+3.95 \phi_{\mathrm{p}}{ }^{1.54}}} \\
\Delta_{\mathrm{s}}=0.865\left(\left(\frac{R}{R_{\mathrm{g}}}\right)^{2}+3.95\left(\frac{R}{R_{\mathrm{g}}}\right)^{2} \phi_{\mathrm{p}}{ }^{1.54}\right)^{-0.44} R
\end{gathered}
$$

These classic or full sphere-sphere and sphere-wall depletion potentials are shown in Fig. 7. The Derjaguin approximation holds reasonably well as the sphere-wall interaction is almost twice as large as the sphere-sphere interaction.

However, we discovered that the depletion potential as outlined above does not accurately describe the phase behaviour of our system, see Fig. 2. Recently, the effect of weak depletion, i.e. when the probability of polymers residing at the surface of a colloidal particle is small but non-zero, was studied in detail by Tuinier and co-workers. ${ }^{20}$ The weak depletion potential differs from the full depletion potential in the value for the depletion layer thickness. As a result of the non-zero probability of the polymer to be on the particle's surface, the depletion layer thickness decreases with a factor of 0.71 in our system. This change has a large effect on the depletion interaction potential as shown in Fig. 7. The effective range of the weak depletion potential as well as the interaction energy at contact $(h=0)$ are smaller for weak depletion. The phase diagram of our experimental system, shown in Fig. 2, can be predicted reasonably well when taking weak depletion into account. Simulations of the phase behaviour and surface adsorption of our system were performed using both the full and the weak depletion potentials.

\subsection{Simulation method}

The onset of bulk aggregation was investigated using Metropolis Monte Carlo simulations using a fixed number of particles $N$, volume $V$ and temperature $T$ (canonical ensemble). ${ }^{34}$ The onset of surface adsorption in particle dispersions was examined using fixed chemical potential $\mu$, volume $V$ and temperature $T$
Table 1 Overview of examined depletion potentials, relative polymer concentrations $\phi_{\mathrm{p}}$ and the obtained intervals at which the adsorption threshold, $\phi_{\mathrm{p}, \text { surface }}{ }^{*}$, and bulk instability, $\phi_{\mathrm{p}, \text { bulk }}{ }^{*}$, appear

\begin{tabular}{llll}
\hline Potential & $\phi_{\mathrm{p}}$ & $\phi_{\mathrm{p}, \text { surface }^{*}}$ & $\phi_{\mathrm{p}, \text { bulk }^{*}}$ \\
\hline Full depletion & $0.48(0.02) 0.56$ & $0.50-0.52$ & $0.54-0.56$ \\
Weak depletion & $0.00,1.40(0.05) 1.60$ & $1.40-1.45$ & $1.55-1.60$
\end{tabular}

(grand canonical ensemble). The canonical simulations were performed using a cubic box with edges $(L)$ of $1920 \mathrm{~nm}$ and periodic boundary conditions in all three dimensions, whereas the grand canonical simulations were made using a box with edges of $1524.5 \mathrm{~nm}, 1524.5 \mathrm{~nm}, 3047 \mathrm{~nm}(X Y Z)$ and periodic boundary conditions applied in the $X$ and $Y$ directions. The particles had a radius of $37 \mathrm{~nm}$, the temperature $298 \mathrm{~K}$ was used throughout, and $N=1000$ particles at volume fraction of $3 \%$ were used in the canonical simulations. The range of the interaction potential was fixed to $1.38 \sigma$ with $\sigma$ being equal to the particle diameter, corresponding to a polymer-to-colloid size ratio of 0.38 . The chemical potential of the particles was determined from the bulk simulations using the Widom particle insertion method.

The full and weak depletion interaction potentials as specified previously were used at selected values of relative polymer concentration as given in Table 1. After equilibration the simulations involved at least $10^{6}$ single particle trial moves per particle with displacement parameter equal to $200 \mathrm{~nm}$.

\subsection{Simulation results}

Fig. 8 shows the structure factor, $S(q)$, obtained from simulations of bulk systems with a weak depletion potential at indicated values of $\phi_{\mathrm{p}}$. In the thermodynamic limit, the structure factor of a phase-separated system diverges as $q$ approaches 0 . For a finite system of $N$ particles, the structure factor of an unstable bulk system limits to $N$ as $q$ approaches 0 . In Fig. 8, the

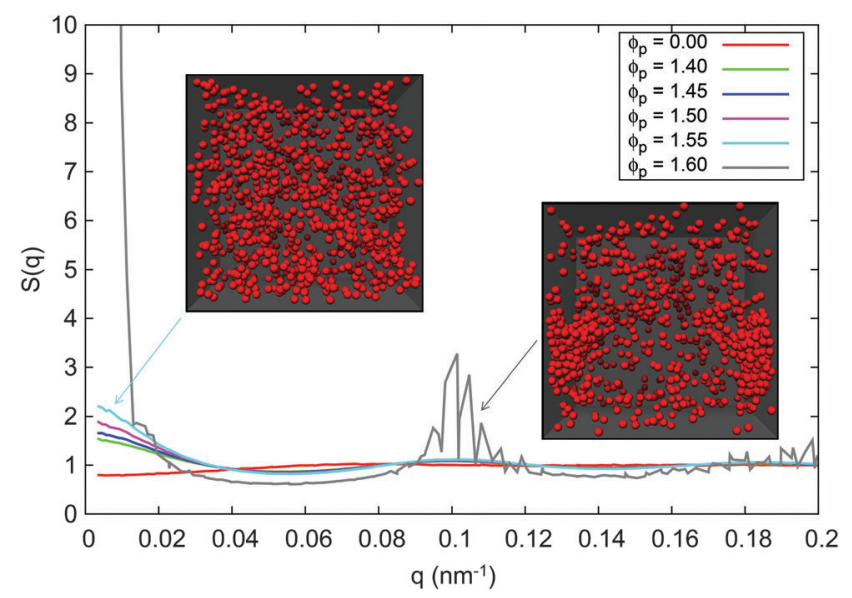

Fig. 8 Structure factor $S(q)$ versus the wave vector $q$ at $3 \mathrm{v} / \mathrm{v} \%$ particles and at indicated polymer volume fractions, $\phi_{p}$, from canonical simulations of the bulk dispersions. $S(q)$ diverges for a phase-separated system. Snapshots from the end of simulations with a weak depletion potential are included for $\phi_{\mathrm{p}}=1.55$ and $\phi_{\mathrm{p}}=1.60$, as indicated by the arrows. 


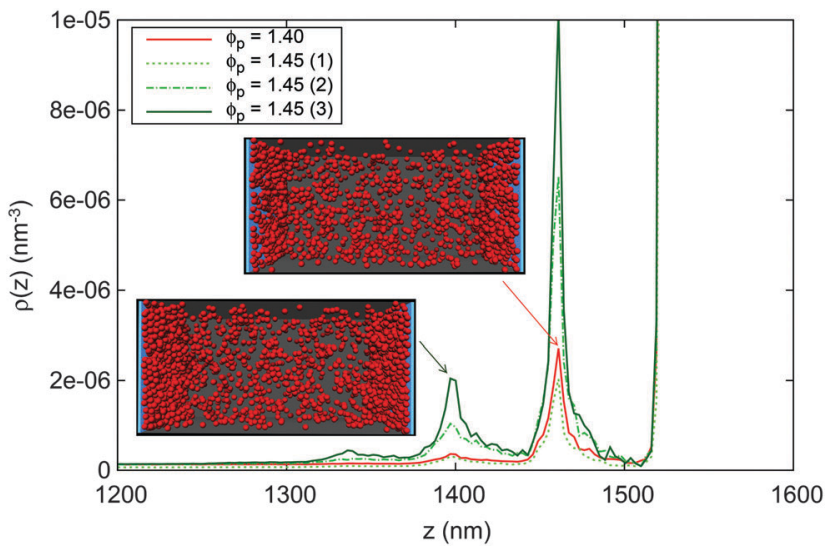

Fig. 9 Number density distributions of particles near one surface, $\rho(z)$, versus distance $z$ from the surface at $3 \mathrm{v} / \mathrm{v} \%$ particles and at indicated polymer volume fractions, $\phi_{\mathrm{p}}$, from grand canonical adsorption simulations. The surface is located at the right end of the graph. Equilibrated result is shown for $\phi_{p}=1.40$. Three successive simulations (each $10^{6}$ Monte Carlo trial moves) at $\phi_{\mathrm{p}}=1.45$ show that this result has not yet converged. Snapshots of simulation box containing two planar surfaces from the end of simulations with a weak depletion potential are included for $\phi_{\mathrm{p}}=1.40$ and $\phi_{\mathrm{p}}=1.45(3)$, as indicated by the arrows.

lower limit of $q$ is equal to $2 \pi / L$ as a consequence of the imposed periodic boundary conditions. The maximum $q$ is slightly smaller than a particle diameter. The structure factor at $\phi_{\mathrm{p}}=0$ is relatively featureless, characteristic for hard-sphere repulsion at low volume fraction. At $\phi_{\mathrm{p}}=1.60$, higher-order maxima (of high-density aggregates) appear and the structure factor diverges. Thus, bulk instability starts to appear between $\phi_{\mathrm{p}}=1.55$ and $\phi_{\mathrm{p}}=1.60$. The value of $S(q=2 \pi / L)=117$ indicates that a large aggregate is formed. Snapshots of final configurations from the canonical simulations at $\phi_{\mathrm{p}}=1.55$ and $\phi_{\mathrm{p}}=1.60$ can also be found in Fig. 8. It is clear that the bulk is stable at $\phi_{\mathrm{p}}=1.55$ but aggregates appear at (and above) $\phi_{\mathrm{p}}=1.60$.

The particle number density distributions as a function of $z$, perpendicular to the surface from the grand canonical simulations with the weak depletion potential are shown in Fig. 9. At the relative polymer volume fraction of 1.40, an adsorbed layer of finite width is obtained and at most two particle layers can be distinguished. However, at $\phi_{\mathrm{p}}=1.45$ the depicted three sequential runs indicate that the result has not yet converged. The adsorbed layer remains growing. Snapshots of final configurations from the simulations of the surface systems for $\phi_{\mathrm{p}}=1.40$ and $\phi_{\mathrm{p}}=1.45(3)$ are included in Fig. 9. At $\phi_{\mathrm{p}}=1.45$ the adsorbed layer contains more particles and is more densely packed than at lower polymer volume fraction. It is expected that a homogeneous high density phase bridging the surfaces would have been obtained at equilibrium. Thus, the surfaceinduced instability appears between $\phi_{\mathrm{p}}=1.40$ and $\phi_{\mathrm{p}}=1.45$, before the bulk instability.

The intervals of polymer volume fraction at which the onset of surface- and bulk-induced instability appear are summarized in Table 1 . We conclude that the surface-induced instability appears at lower polymer volume fraction than the bulk instability.
For completeness, simulations were also performed with the full depletion potential. The obtained intervals of surfaceinduced and bulk instabilities can be found in Table 1 . The interval of interaction strength where surface adsorption is substantial while the bulk remains one phase is almost nonexistent. This contradicts our experimental results that clearly show that such an interval does indeed exist. Furthermore, our results confirm that weak depletion is essential for an accurate representation of our experimental system and, consequently, that classical (full) depletion theory falls short in this case. Finally, the obtained experimental results serve as a validation of weak depletion theory ${ }^{20}$ for systems consisting of stearyl silica spheres in cyclohexane with PDMS as depletant.

\section{Conclusions}

We have shown that surface adsorption precedes bulk aggregation for particles and substrates that have the same material and surface properties. The strength of the particle-particle and particle-surface interactions could be controlled simultaneously by addition of depletion polymer. Multiple layers of particles were found to adsorb onto the substrates as the depletion interaction was increased. Monte Carlo simulations with recently developed weak depletion theory accurately describe the phase behaviour of our system and quantitatively support the experimental observations.

Our experimental and simulation results correspond well with predictions from theory and simulations by Linse and Wennerström, and show that indeed an interval in the interaction strength is present, at which surface adsorption is significant while bulk aggregation is negligible.

\section{Appendices}

\section{Appendix A: radius of gyration of PDMS}

The radius of gyration of PDMS was calculated following Vincent. ${ }^{26,27}$ The radius of gyration, $R_{\mathrm{g}}$, of a depletion polymer is given by:

$$
R_{\mathrm{g}}=r_{\mathrm{g}}^{\mathrm{o}} r^{0.1}
$$

Here, $r_{\mathrm{g}}^{\mathrm{o}}$ is the unperturbed value of the radius of gyration and $r$ the number of effective segments per polymer chain. $r$ is linked to the statistical segment length $l$ through the extended polymer length $L$ :

$$
L=r l
$$

$r$ itself is defined by constants that are related to the nature of the polymer:

$$
r=\left(\frac{0.408 s}{A M_{\mathrm{s}}}\right)^{2} M_{\mathrm{w}}
$$

Here, $M_{\mathrm{s}}$ is the molar mass of the polymer repeat unit, $A$ an empirical constant characteristic of the polymer chains in a $\theta$-solvent, $s$ the length of each segment and $M_{\mathrm{w}}$ the molecular weight of the polymer. The unperturbed value of the radius of 
gyration, $r_{\mathrm{g}}^{\mathrm{o}}$, can be calculated from:

$$
r_{\mathrm{g}}^{\mathrm{o}}=\frac{A^{2} M_{\mathrm{s}}}{0.408 s} \sqrt{r}
$$

The values of $A, M_{\mathrm{s}}$ and $s$ can be found in literature and have the following values for PDMS: ${ }^{26}$

$$
\begin{aligned}
A & =0.027 \mathrm{~nm} \sqrt{\mathrm{mol}} \sqrt{\mathrm{g}}-1 \\
M_{\mathrm{S}} & =74 \mathrm{~g} \mathrm{~mol}^{-1} \\
s & =0.25 \mathrm{~nm}
\end{aligned}
$$

PDMS used here had a molecular weight of $95000 \mathrm{~g} \mathrm{~mol}^{-1}$. Together, these values yield:

$$
\begin{gathered}
r=248 \\
r_{\mathrm{g}}^{\mathrm{o}}=8.32 \mathrm{~nm}
\end{gathered}
$$

The calculated value of the radius of gyration of PDMS with a molecular weight of $95000 \mathrm{~g} \mathrm{~mol}^{-1}$ is:

$$
R_{\mathrm{g}}=r_{\mathrm{g}}^{\mathrm{o}} r^{0.1}=14.4 \mathrm{~nm}
$$

\section{Appendix B: van der Waals attraction}

The results in Section 3.2, show that the surface adsorption of particles increases with increasing depletant concentration and thus with increasing attraction between the particles. However, it was also found that surface adsorption occurs even in the absence of depletion polymer. Therefore, the reference condition of a pure hard-wall interaction ${ }^{18}$ is not strictly achieved in our model system in the absence of depletant. Adsorption in the absence of depletion polymer very likely occurs as a consequence of the van der Waals attraction.

The van der Waals attraction $W_{\text {ss }}(h)$ between two identical spheres with radius $a$ at a small separation $h$ between the surfaces of the particles, is given by: ${ }^{35}$

$$
W_{\mathrm{ss}}(h)=-\frac{A}{12}\left[\frac{a}{h}\right] \text { for } h \ll a
$$

Here, $A$ is the Hamaker constant. The sphere-wall attraction, $W_{\text {sw }}(h)$ is twice as large as in eqn (16):

$$
W_{\mathrm{sw}}(h)=-\frac{A}{6}\left[\frac{a}{h}\right] \text { for } h \ll a
$$

Eqn (16) and (17) can be used to estimate van der Waals attraction in stearyl silica-cyclohexane systems. The Hamaker constant of stearyl silica in cyclohexane is about $0.15 \mathrm{kT}$ at a temperature of $298 \mathrm{~K} .{ }^{36}$ Eqn (16) and (17) then become:

$$
\begin{aligned}
& \beta W_{\mathrm{ss}}(h) \approx-\frac{0.15}{12}\left[\frac{a}{h}\right] \\
& \beta W_{\mathrm{sW}}(h) \approx-\frac{0.15}{6}\left[\frac{a}{h}\right]
\end{aligned}
$$

For a sphere radius $a=37 \mathrm{~nm}, \beta W_{\mathrm{ss}}(h)$ and $\beta W_{\mathrm{sw}}(h)$ are presented graphically as a function of separation $h$ in Fig. 10. A stearyl chain extends $1.5 \mathrm{~nm}$ in cyclohexane from the surface

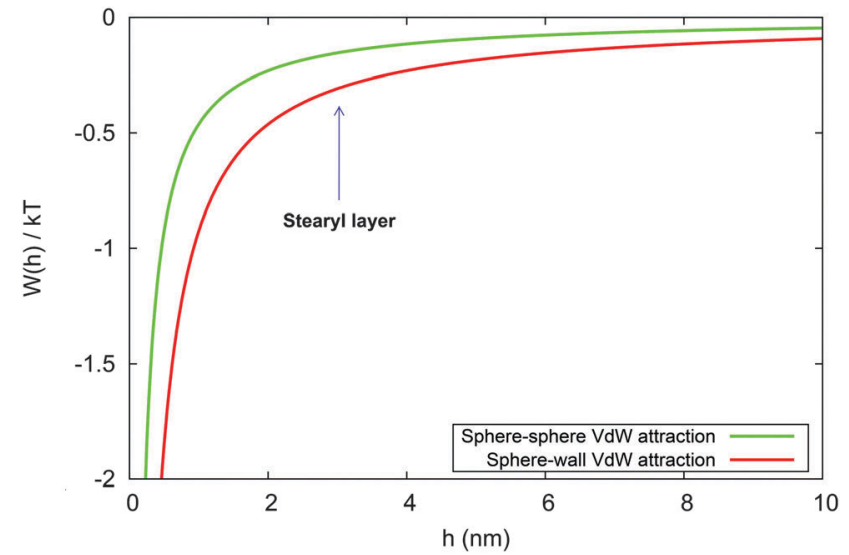

Fig. 10 Sphere-sphere and sphere-wall van der Waals attraction versus surface-to-surface distance $h$ of stearyl silica spheres dispersed in cyclohexane with a diameter of $74 \mathrm{~nm}$. An arrow indicates the (maximal) separation as a result of the stearyl layer.

of the silica particle. ${ }^{36}$ The minimum separation between two stearyl silica spheres (or one stearyl silica sphere and a stearyl silica wall) is thus about $3 \mathrm{~nm}$. For our dispersion, the spheresphere van der Waals attraction has a value of $0.15 k T$ at $h=3 \mathrm{~nm}$. The sphere-wall van der Waals attraction is twice as strong and has a value of $0.3 k T$.

This $0.3 k T$ is a lower-bound as various factors can - and very likely will - strengthen the sphere-wall attraction. Examples of these factors are non-spherical shape and surface irregularities that increase the contact areas, and imperfections in the stearyl coating on the surfaces.

\section{Acknowledgements}

Prof. H. Wennerström is thanked for helpful discussions; SO also thanks Dr T. Halthur and Dr M. Yanez Arteta for experimental support and acknowledges financial support from the Erasmus programme for a stay at Lund University. LP, PL and TN acknowledge Swedish Foundation for Strategic Research (SSF) for financial support via framework grant RMA08-0056.

\section{References}

1 D. F. Evans and H. Wennerström, The Colloidal Domain: Where Physics, Chemistry, Biology, and Technology Meet, Wiley-VCH, 2nd edn, 1999.

2 A. Adamczyk, Adsorption of Particles: Theory in Encyclopedia of Surface and Colloid Science, Taylor \& Francis, 2nd edn, 2006.

3 P. Jiang, J. F. Bertone, K. S. Hwang and V. L. Colvin, Chem. Mater., 1999, 11, 2132-2140.

4 J. Kleinert, S. Kim and O. D. Velev, Langmuir, 2010, 26, 10380.

5 J. M. Meijer, F. Hagemans, L. Rossi, D. V. Byelov, S. I. R. Castillo, A. Snigirev, I. Snigireva, A. P. Philipse and A. V. Petukhov, Langmuir, 2012, 28, 7631-7638. 
6 H. Okudera and A. Hozumi, Thin Solid Films, 2003, 434, 62-68.

7 H. Okudera and Y. Yokogawa, Thin Solid Films, 2001, 401, 124-130.

8 H. Shin, M. Agarwal, M. R. D. Guire and A. H. Heuer, Acta Mater., 1998, 46, 801-815.

9 P. Lipowsky, S. Jia, R. C. Hoffman and N. Y. Jin-Phillip, Int. J. Mater. Res., 2006, 97, 607-613.

10 P. Lipowsky, N. Hedin, J. Bill, R. C. Hoffmann, A. Ahniyaz, F. Aldinger and L. Bergstrom, J. Phys. Chem. C, 2008, 112, 5373-5383.

11 M. Dijkstra, R. van Roij, R. Roth and A. Fortini, Phys. Rev. E: Stat., Nonlinear, Soft Matter Phys., 2006, 73, 041404.

12 J. M. Brader, R. Evans and M. Schmidt, Mol. Phys., 2003, 101, 3349-3384.

13 W. K. Wijting, N. A. M. Besseling and M. A. Cohen Stuart, Phys. Rev. Lett., 2003, 90, 17-20.

14 A. D. Dinsmore, P. B. Warren, W. C. K. Poon and A. G. Yodh, Europhys. Lett., 1997, 40, 337-342.

15 A. D. Dinsmore, A. G. Yodh and D. J. Pine, Phys. Rev. E: Stat. Phys., Plasmas, Fluids, Relat. Interdiscip. Top., 1995, 52, 4045-4057.

16 P. D. Kaplan, J. L. Rouke, A. G. Yodh and D. J. Pine, Phys. Rev. Lett., 1994, 72, 582-585.

17 W. C. K. Poon and P. B. Warren, Europhys. Lett., 1994, 28, 513-518.

18 P. Linse and H. Wennerström, Soft Matter, 2012, 8, 2486-2493.

19 A. K. van Helden, J. W. Jansen and A. Vrij, J. Colloid Interface Sci., 1981, 81, 354-368.

20 Details will be reported in future work by R. Tuinier, S. Ouhajji and $\mathrm{P}$. Linse. A preprint version is available at request.
21 W. Stöber and A. Fink, J. Colloid Interface Sci., 1968, 26, 62-69.

22 D. M. E. Thies-Weesie, Sedimentation and Liquid Permeation of Inorganic Colloids, PhD thesis, Utrecht University, 1995.

23 A. K. van Helden and A. Vrij, J. Colloid Interface Sci., 1980, 78, 312-329.

24 N. A. M. Verhaegh, D. Asnaghi and H. N. W. Lekkerkerker, Phys. A, 1999, 264, 64-74.

25 E. H. A. de Hoog, L. I. de Jong-van Steensel, M. M. E. Snel and H. N. W. Lekkerkerker, Langmuir, 2001, 17, 5486-5490.

26 B. Vincent, Colloids Surf., 1990, 50, 241-249.

27 B. Vincent, J. Edwards, S. Emmett and R. Croot, Colloids Surf., 1988, 31, 267-298.

28 N. A. M. Verhaegh, D. Asnaghi, H. N. W. Lekkerkerker, M. Giglio and L. Cipelletti, Phys. A, 1997, 242, 104-118.

29 H. N. W. Lekkerkerker and R. Tuinier, Colloids and the Depletion Interaction, Springer, 1st edn, 2011.

30 F. Tiberg and M. Landgren, Langmuir, 1993, 9, 927-932.

31 J. A. de Feijter, J. Benjamins and F. A. Veer, Biopolymers, 1978, 17, 1759-1772.

32 A. M. Nechifor, A. P. Philipse, F. de Jong and J. P. M. van Duynhoven, Langmuir, 1996, 12, 3844-3854.

33 R. Tuinier, D. G. A. L. Aarts, H. H. Wensink and H. N. W. Lekkerkerker, Phys. Chem. Chem. Phys., 2003, 5, 3707-3715.

34 J. Reščič and P. Linse, J. Comput. Chem., 2015, 36, 1259-1274.

35 Fundamentals of Interface and Colloid Science - Volume I: Fundamentals, ed. J. Lyklema, Academic Press, 1991.

36 J. W. Jansen, A. Vrij and C. G. de Kruif, J. Colloid Interface Sci., 1986, 114, 471-480. 